
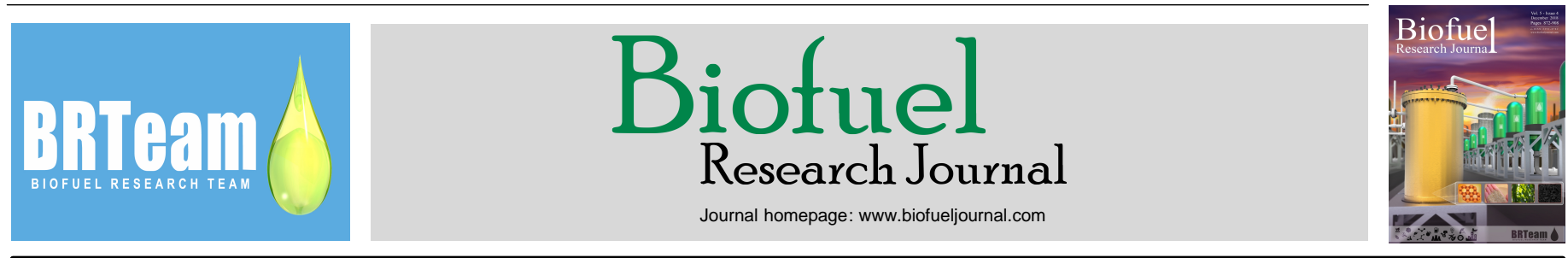

Original Research Paper

\title{
An experimental investigation on the long-term compatibility of preheated crude palm oil in a large compression ignition diesel engine
}

\author{
Emiliano Pipitone ${ }^{1, *}$, Antonio Costanza ${ }^{2}$ \\ ${ }^{1}$ Department of Industrial and Digital Innovation, University of Palermo, Viale delle Scienze, 90128, Palermo, Italy. \\ ${ }^{2}$ Istituto Nazionale di Geofisica e Vulcanologia - Osservatorio Nazionale Terremoti, Roma (RM), Italy.
}

\section{HIGHLIGHTS}

$>$ Effect of crude palm oil preheating temperature was investigated on a modern large $\mathrm{CI}$ engine. $>$ Engine wear and carbon deposits were evaluated during $300 \mathrm{~h}$ nominal power operation.

$>$ Preheating at $60^{\circ} \mathrm{C}$ produced higher carbon deposits and faster lubricant degradation. $>$ Compared with $60{ }^{\circ} \mathrm{C}$, preheating at $80^{\circ} \mathrm{C}$ reduced carbon deposits by $27 \%$ and extended engine operation time by $30 \%$.

\section{Article history:}

Received 7 June 2018

Received in revised form 7 September 2018

Accepted 3 October 2018

Available online 1 December 2018

\section{Keywords:}

Compression ignition engine

Straight vegetable oil

Crude palm oil

Biofuel compatibility

Durability test

Engine lubricant

\section{GRAPHICAL ABSTRACT}

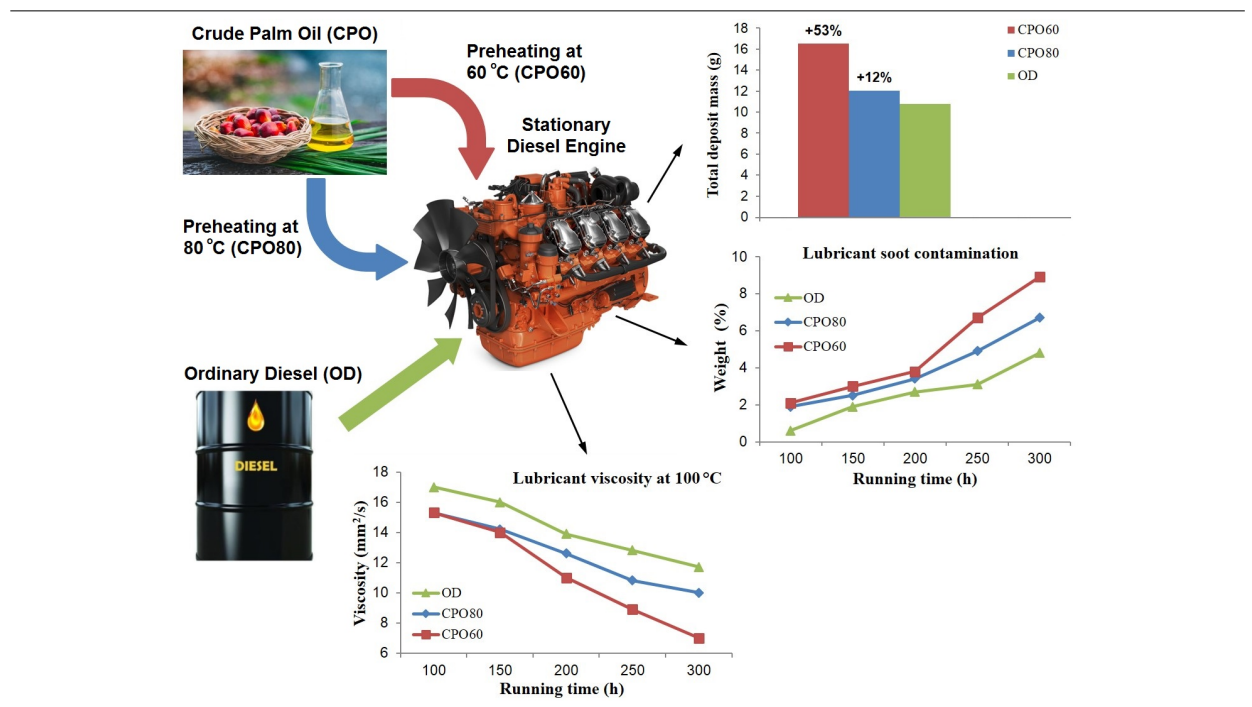

\section{ARTICLE INFO}

\begin{abstract}
An experimental study was carried out on a large stationary compression ignition engine to evaluate the long-term compatibility and durability issues associated with the use of crude palm oil as fuel. Two different preheating temperatures $\left(60\right.$ and $\left.80{ }^{\circ} \mathrm{C}\right)$ were adopted to assess the potential improvements related to lower fuel viscosity. The results obtained, in terms of in-cylinder carbon deposits and engine wear, were compared with the results obtained using ordinary diesel fuel. For each fuel and preheating temperature, the engine was operated for 300 consecutive $\mathrm{h}$, during which several engine lubricant samples were collected and analysed to determine soot and fuel contaminations, viscosity alterations, and the presence of different wear-related metals (measured by atomic absorption spectroscopy). At the end of each $300 \mathrm{~h}$ endurance test, the carbon deposits were scraped from engine cylinders and examined through thermogravimetric analysis (TGA). It was found that the use of crude palm oil caused a remarkable increment of in-cylinder deposits formation compared with ordinary diesel. The lubricant analysis also revealed a faster viscosity degradation and consequent stronger engine wear, above all with the lower preheating temperature. The results obtained confirmed that continuous engine operation (i.e., without a complete lubricant change) should be carefully reduced when fuelling with crude palm oil. Moreover, the findings obtained herein confirmed the favourable impacts of fuel preheating at $80^{\circ} \mathrm{C}$ compared to $60{ }^{\circ} \mathrm{C}$, i.e., reduced carbon deposits by $27 \%$ and extended engine operation time by $30 \%$.
\end{abstract}

(ㄷ) 2018 BRTeam. All rights reserved.

* Corresponding author at: Tel.: +39 9123897280

E-mail address: emiliano.pipitone@unipa.it

Please cite this article as: Pipitone E., Costanza A. An experimental investigation on the long-term compatibility of preheated crude palm oil in a large compression ignition diesel engine. Biofuel Research Journal 20 (2018) 900-908. DOI: 10.18331/BRJ2018.5.4.5 


\section{Introduction}

The fluctuating price of petroleum-derived fuels and the adoption of more and more severe pollutant emission regulations induced to look at biofuels as a promising alternative to conventional fossil fuels. Biofuels, mainly constituted by biomass, biogas, primary alcohols, vegetable oils, and biodiesel, offer the advantage of a renewable energy source, being derived from agricultural and plant resources, and a lower environmental impact, above all if the $\mathrm{CO}_{2}$ emission is concerned. Human activities, above all concerning the use of fossil fuels for energy production and transport sector, increased the world atmosphere $\mathrm{CO}_{2}$ concentration from $280 \mathrm{ppm}$ in the pre-industrial era to the current 411 ppm (Earth's CO2 Home Page, 2018), causing the well-known global warming phenomenon. The use of biofuels in place of fossil fuels would substantially help to mitigate this phenomenon thanks to their closed carbon cycle, since the $\mathrm{CO}_{2}$ released by their combustion is absorbed by the growing plants and crops employed for their production (Srivastava and Prasad, 2000).

Among the various biofuels, vegetable oils (both edible and non-edible) and biodiesels seem to represent the most suitable diesel fuel replacement for compression ignition $(\mathrm{CI})$ engines. Vegetable oils are directly derived from crops through simple mechanical and thermal processes (Sidibé et al., 2010), while biodiesel is obtained by the transesterification reaction, i.e., the reaction of a fat or oil (fresh or recycled) with a short-chain alcohol to form esters and glycerol (Srivastava and Prasad, 2000; Agarwal, 2007; Ong et al., 2011; Sharon et al., 2012a). Both vegetable oils and biodiesel are biodegradable, non-toxic, and essentially free from sulphur (Srivastava and Prasad, 2000; Agarwal, 2007), hence, they constitute a valuable and environmentally friendly substitute to fossil fuels. However, in order to be successfully employed in the current CI engines, their viscosity (which affects both jet atomization and penetration and hence, strongly influences both combustion process and pollutant formation) and auto-ignition characteristics (represented by cetane number and affects the rate of heat released by combustion) should be as near as possible to those of the ordinary diesel (OD) fuel.

In fact, biodiesel, also known as the mono alkyl ester of fatty acids, is characterized by viscosity, volatility and cetane number very close to those of conventional diesel fuel (Srivastava and Prasad, 2000; Agarwal, 2007; Ong et al., 2011), hence allowing to be immediately employed in the current $\mathrm{CI}$ engines. Methyl esters derived from Jatropha Curcas oil (Ong et al., 2011), coconut oil (Shaheed and Swain, 1999), palm oil (Masjuki et al., 1996; De Almeida et al., 2002; Ong et al., 2011; Ndayishimiye and Tazerout, 2011; Sharon et al., 2012b), rapeseed, soybean, and hazelnut oils (Çelikten et al., 2010; Gokalp et al., 2011; Çelikten et al., 2012), as well as cottonseed oil (Aydin and Bayindir, 2010), have been widely reported in the literature and represent a few examples of the great number of vegetable oil methyl esters available (Graboski and McCormick, 1998). These methyl esters are used in neat form or blended with OD.

The experimental results shown in the literature are really encouraging, since even without performing any injection parameters optimization for the tested biodiesels, both engine power and efficiency proved to remain comparable with those of OD. These could be explained by the favourable fuel properties and the high oxygen content of biodiesel (about $10 \%$ by weight) resulting in more efficient jet atomization/mixing and consequently more complete combustion. This in turn leads to reduced $\mathrm{HC}, \mathrm{CO}$, and PM emissions and therefore, biodiesel has the potential to reduce atmospheric pollutions when used for power generation in the transportation sector (Iodice and Senatore, 2016), especially in densely populated or industrialized areas (Iodice et al., 2018). The most important drawback associated with biodiesel application is the moderate increase in $\mathrm{NO}_{\mathrm{X}}$ emissions owing to the oxygen content of the fuel.

On the other hand, in spite of the many advantages of biodiesel, its production is still costly in many parts of the world, thus preventing its penetration and diffusion in the global market. A reasonable alternative could be the direct use of crude vegetable oils. Nevertheless, there are also some drawbacks attributed to the application of straight vegetable oils such as low volatility and high viscosity (about 10 to 15 times the viscosity of diesel fuel) (Shaheed and Swain, 1999; Srivastava and Prasad, 2000; Altin et al., 2001; Agarwal, 2007; Sidibé et al., 2010; Esteban et al., 2012; Sharon et al., 2012a). These could cause improper jet atomization and mixing of fuel with air, cold start problems, misfires and ignition delay, generation of carbon deposits, injector coking, piston ring sticking as well as lubrication oil dilution and degradation (Srivastava and Prasad, 2000; Altin et al., 2001; Agarwal, 2007;
Sidibé et al., 2010; Ong et al., 2011; Sharon et al., 2012a). In internal combustion engines, carbon deposits originate from the incomplete combustion of fuel and thermal cracking of both fuel and lubricant inside the cylinder. These deposits are mainly constituted by carbon residues (commonly referred to as ash), carbonaceous mixtures (soot) and oxygenated resinous substances.

To solve the problems associated with the direct use of crude vegetable oils in CI engines, different treatments may be employed such as preheating (Nwafor, 2003; Agarwal and Agarwal, 2007; Yilmaz and Morton, 2011), blending with diesel fuel (Agarwal and Agarwal, 2007; Franco and Nguyen, 2011; Yilmaz, 2011; Yusaf et al., 2011), micro-emulsion (Kumar et al., 2009; Kibbey et al., 2014), and pyrolysis (or thermal cracking) (Maher and Bressler, 2007; Kubátová et al., 2011). Among these approaches, fuel preheating is obviously the most economic and practical choice as it can be easily performed in real time on existing industrial or vehicle diesel engines.

Several crude vegetable oils of different origins (i.e., sunflower, cottonseed, soybean, corn, rapeseed, Jatropha Curcas, rice bran, coconut, Palm) have been successfully tested in CI engines (Shaheed and Swain, 1999; Altin et al., 2001; Agarwal and Agarwal, 2007; Saravanan et al., 2007; Canakci et al., 2009; Sidibé et al., 2010; Yusaf et al., 2011). The results obtained in these studies were indicative of favourable performance parameters in terms of both power generation and energy conversion efficiency. Moreover, the environmental impacts attributed with the direct use of these oils were also found promising leading to regulated emissions $\left(\mathrm{CO}, \mathrm{HC}, \mathrm{NO}_{\mathrm{X}}, \mathrm{PM}\right)$ comparable with those of $\mathrm{OD}$, with some variations depending on a given vegetable oil used. However, the higher viscosity and lower volatility of crude vegetable oils were also highlighted as the reasons behind occasional increases in some emissions in comparison with diesel fuel.

A key issue not yet totally resolved is the long-term operation compatibility of crude vegetable oil in both vehicle and stationary engines. As an example and as mentioned earlier, the deposits formed in the combustion chamber in response to the utilization of these oils could strongly influence in-cylinder thermodynamic processes and may seriously compromise both engine performance and emissions (Kalam and Masjuki, 2004; Shu et al., 2012). More specifically, their high viscosity and the consequent poor fuel jet nebulization and incomplete combustion could increase engine soot emissions as well as in-cylinder carbon deposits (Kalam and Masjuki, 2004; Shu et al., 2012; Liaquat et al., 2013; Mofijur et al., 2013). An excessive production of carbon deposits could lead to increased engine compression ratio and gas leakage through valve seats (Heywood, 1988). Under the most severe conditions, engine breakdown cases could also take place (Husnawan et al., 2009). Moreover, due to their lower thermal conductivity, carbon deposits may also cause increases in incylinder temperature, thus increasing $\mathrm{NO}_{\mathrm{X}}$ emissions by up to $30 \%$ (Heywood, 1988; Kalam and Masjuki, 2004; Ye et al., 2007). Deposits or coking at injectors' tips could further deteriorate fuel injection process resulting in poor fuel atomization and mixing with air. This in turn results in misfires (and hence, power loss) as well high particulate and hydrocarbon emissions.

In addition to deposit formation, engine wear problems may also arise due to the use of straight vegetable oils. More specifically, the alreadymentioned poor nebulization effect is often followed by deep in-cylinder penetration of fuel jet, which could result in a serious contamination and dilution of the lubricant, whose properties may deteriorate causing high friction losses and engine wears (Caine et al., 2004; Agarwal, 2007; Basinger et al., 2010; Liaquat et al., 2013). A high formation of carbon deposits may also contribute to the deterioration of lubricant properties, thus increasing the mechanical friction and the related wears (Agarwal, 2007). All these troubles should be carefully evaluated before fuelling $\mathrm{Cl}$ engines with crude vegetable oils for heavy or long term operations.

Although several reports are available in the literature investigating the durability of CI engines fuelled with biodiesel (Husnawan et al., 2009; Fazal et al., 2011; Wander et al., 2011; Mofijur et al., 2013), little could be found on the use of straight (crude) vegetable oils (Basinger et al., 2010), and in particular on crude palm oil (CPO). It should be noted that even those research works are limited to small engines and short-term operations (Lim et al., 2002; Kalam and Masjuki, 2004). In better words, to the best of our knowledge, the effects of prolonged use (i.e., for at least 100 consecutive 
hours) of CPO on large engines have not been documented yet. In light of that, a methodical experimental investigation on a large stationary CI engine was set herein with the aim to ascertain the influences of $\mathrm{CPO}$ usage on both in-cylinder deposits and engine wears during $300 \mathrm{~h}$ endurance tests.

\section{Materials and Methods}

The palm oil used in the tests was refined based on the Short-Mix process (Erickson, 1990), and its properties are presented in Table 1. Figure 1 reports on the measured kinematic viscosity of both the CPO and diesel fuel used in the tests, as a function of temperature. As can be observed, CPO is characterized by a high viscosity at low temperatures, i.e., it is almost solid at the ambient temperature, reaching the viscosity of $40 \mathrm{cSt}$ at $40^{\circ} \mathrm{C}$. The adoption of a viscosity reduction measure is therefore mandatory for using palm oil in a $\mathrm{CI}$ engine, above all when extended running periods are planned. Considering the strong influence of temperature on palm oil viscosity (as shown in Figure 1), the most simple method to improve its fluidity would be by heating. In light of that, the effect of preheating temperature on both in-cylinder deposits and engine wear in response to the prolonged use of $\mathrm{CPO}$ in a stationary large $\mathrm{CI}$ engine was investigated in the present study.

Table 1.

Main properties of the $\mathrm{CPO}$ used in the present study.

\begin{tabular}{llcc}
\hline Property & Method & Value & Unit \\
\hline Density at $50 .{ }^{\circ} \mathrm{C}$ & ISO 3675 & 890.5 & $\mathrm{~kg} / \mathrm{m}^{3}$ \\
Density at $15^{\circ} \mathrm{C}$ & ISO 3675 & 890 & $\mathrm{~kg} / \mathrm{m}^{3}$ \\
Flash point & EN 22719 & 256 & ${ }^{\circ} \mathrm{C}$ \\
Conradson carbon residue (CCR) & ASTM D 4530 & 0.18 & $\% \mathrm{wt}$. \\
Contamination & DIN EN 12662 & 0.74 & $\mathrm{mg} / \mathrm{kg}$ \\
Ash & ISO 6245 & 0.01 & $\% \mathrm{wt}$. \\
Iodine number & DIN 53241-1 & 56 & $\mathrm{~g} / 100 \mathrm{~g}$ \\
Acid value & ASTM D 664 & 6.75 & $\mathrm{mg} \mathrm{KOH} / \mathrm{g}$ \\
Phosphorus & ASTM D 3231 & 10 & $\mathrm{mg} / \mathrm{kg}$ \\
Water & ISO 12937 & 659 & $\mathrm{mg} / \mathrm{kg}$ \\
Lower heating value & ASTM D 240 & 8828 & $\mathrm{kcal} / \mathrm{kg}$ \\
Higher heating value & ASTM D 240 & 9402 & $\mathrm{kcal} / \mathrm{kg}$ \\
Total Sulphur & ASTM D 5453 & $<1$ & $\mathrm{mg} / \mathrm{kg}$ \\
\hline
\end{tabular}



Fig. 1. Kinematic viscosity of crude palm oil (CPO) and ordinary diesel (OD) fuel, as a function of temperature.

To achieve that, a wide series of test and measurements were performed adopting two different preheating temperatures, i.e., $60{ }^{\circ} \mathrm{C}$ and $80{ }^{\circ} \mathrm{C}$ (hereinafter CPO60 and CPO80, respectively). For comparison purposes, the same tests were replicated using OD, whose viscosity at $40{ }^{\circ} \mathrm{C}$ was about 2.5 cSt (Figure 1). The same diagram shows that at $60{ }^{\circ} \mathrm{C}$ and $80{ }^{\circ} \mathrm{C}$, palm oil viscosity was reduced to $21.4 \mathrm{cSt}$ and $11.8 \mathrm{cSt}$, respectively, thus making pumping and injection possible. The tests were conducted on a Scania DC16 44A whose main characteristics are tabulated in Table 2. Scania DC16 44A is a large multi-cylinder stationary CI engine dedicated to power production and was connected to a Marelli MJB355SB generator in the present study. This constitutes another innovative aspect of the present work, since according to the existing literature, the research on the use of CPO has been limited to small single cylinder engines (Lim et al., 2002; Kalam and Masjuki, 2004; Basinger et al., 2010). This is important, as sometimes the results obtained on small systems are hardly extensible to large direct injection CI engines. Moreover, the engine employed herein was compatible with both running on $100 \%$ biodiesel as well as mixtures of diesel fuel and straight vegetable oil.

Table 2.

Engine specifications (www.scania.com)

\begin{tabular}{ll}
\hline No. of cylinders & 8 \\
Engine arrangement & $\mathrm{V} 90^{\circ}$ \\
Bore & $127 \mathrm{~mm}$ \\
Stroke & $154 \mathrm{~mm}$ \\
Total displacement & $15.6 \mathrm{~L}$ \\
Compression ratio & $16: 1$ \\
No. of valves per cylinder & 4 \\
Type of injection & Direct Injection, Unit injector technology \\
Rated power & $481 \mathrm{~kW}$ \\
Cooling & Water cooled \\
Weight (excl. oil and water) & $1290 \mathrm{~kg}$ \\
\hline
\end{tabular}

CPO preheating was performed prior to its introduction into the pump and fuel lines. The unavoidable heat transfer from engine head to fuel lines also caused a further temperature increment. This means that the actual temperature reached by $\mathrm{CPO}$ just before injection was higher than the preheating temperature but measuring this temperature during normal operation of the engine was not possible. Nevertheless, measurements of the fuel temperature in the returning line (which were possible only during the set-up phase) revealed an increment of about $10{ }^{\circ} \mathrm{C}$ with respect to the preheating temperature adopted.

For each tested fuel and preheating temperature, the engine was operated at the constant speed of $1500 \mathrm{rpm}$ for 300 consecutive $\mathrm{h}, 14 \mathrm{~h}$ each day. Dealing with continuous engine operation, power output was limited, as recommended by the engine manufacturer, to $70 \%$ of rated power, i.e. roughly $337 \mathrm{~kW}$, corresponding to a brake mean effective pressure (BMEP) of 17.3 bar. At the beginning and at the end of every working day, the engine was operated for $15 \mathrm{~min}$ with OD with the aim to maintain both fuel pump and fuel line clean. After each test period of $300 \mathrm{~h}$, each cylinder of the engine was disassembled to scrape out the carbon deposits from piston crowns, cylinder heads, valves, and injectors. Moreover, with the aim to limit the influence of each test on the subsequent test as much as possible, at the end of each $300 \mathrm{~h}$ test period, the entire charge of lubricating oil (40 L) was changed together with oil filter. Moreover, the oil purifier of the engine was cleaned up and the injector tips were replaced.

With the aim to characterize the composition of the collected deposits, a thermogravimetric analysis (TGA) was performed using a NETZSCH STA 409 Thermal Analyser. The procedure included a progressive heating of the deposit sample and simultaneous measurement of its weight change as function of temperature. The weight change was caused through the interaction of the sample with its surrounding atmosphere until weight stabilization. The heating process was repeated twice, employing two different kinds of atmospheres: a non-oxidative atmosphere for the estimation of the volatile fraction and an oxidative atmosphere to determine the carbon fraction.

\section{Results and Discussion}

\subsection{Engine deposits}

For each considered fuel and preheating temperature and following a running period of 300 consecutive $h$, deposits were carefully removed from 
the cylinder heads, piston crowns, valves, and injectors. Each collected carbon deposit was dried in an oven at $105{ }^{\circ} \mathrm{C}$ to remove water and was successively cooled in a desiccator. Figure 2 reports on the amount of deposits collected by using the two preheated palm oils and the OD. As can be observed, the use of CPO60 caused a remarkable increment of in-cylinder deposits (53\%) with respect to $\mathrm{OD}$, while the higher preheating temperature of $80{ }^{\circ} \mathrm{C}$ substantially reduced the formation of deposits (12\% increment in comparison with OD).



Fig. 2. Total amount of deposits collected for each preheating temperature and fuel tested.

Incomplete combustion of fuel and thermal cracking of both fuel and lubricant are regarded as the main reason behind the formation of carbon deposits. Considering that the entire lubricant charge was substituted before each fuel test, the considerable carbon deposits increment recorded using CPO60 could be entirely ascribed to the high viscosity of the fuel, (roughly 9 times the viscosity of $\mathrm{OD}$ ). This resulted in a very poor jet nebulization, thus increasing the number and size of unburned fuel droplets in the combustion chamber and consequently causing more carbon deposits. Preheating CPO up to $80^{\circ} \mathrm{C}$ reduced fuel viscosity by half, thus improved fuel jet nebulization and reduced in cylinder deposits.

Figure 3a reveals the weight loss trend of each deposit sample during the non-oxidative heating. The recorded mass reduction, between 60 and $70 \%$, represents the amount of volatile substances of each deposit sample. The successive heating of each residual sample mass was performed in the oxidative environment (Figure 3b). The second mass loss represents the amount of nonvolatile reactive substances present in each deposit sample, i.e., the carbon fraction. Hence, the remaining mass represents the amount of non-volatile and non-reactive substances of each deposit sample, usually referred to as ash. The summary of the TGA results is summarized in Figure 4. Accordingly, it could be concluded that the low preheating temperature could cause substantial increases in the ash content of the in-cylinder deposits. Considering the high thermal insulating effect of ashes and the increment in the total amount of incylinder deposit recorded using CPO60 (Fig. 2), higher in-cylinder temperatures and consequently increased $\mathrm{NO}_{\mathrm{X}}$ emissions would be expected (Ye et al., 2007). Preheating CPO to $80^{\circ} \mathrm{C}$ resulted in a similar carbon fraction to that of OD (i.e., 29\%), while prehearing at $60{ }^{\circ} \mathrm{C}$ led to a slightly higher fraction of $31 \%$. This confirmed that a more complete combustion was achieved by increasing the preheating temperature of CPO.

Separately weighing the deposits collected from valves, injectors, cylinder heads and piston crowns, also allowed the evaluation of the in-cylinder distribution of the carbon deposit. The improvements (reduction in weight of deposits) caused by increasing preheating temperature from 60 to $80{ }^{\circ} \mathrm{C}$ are shown in Figure 5. More specifically, a carbon deposit reduction of $38 \%$ on cylinder heads, $43 \%$ on engine valves, $30 \%$ on injectors, and $35 \%$ on piston crowns were recorded.

\subsection{Lubricant analysis}

As well known, the basic function of engine lubricants is to reduce mechanical friction between moving elements and prevent their wear. In addition to that, engine lubricants also act as heat transfer agents between combustion-heated parts and heat-dissipating system, sealant between pistons and cylinders, and finally as cleaning agent removing deposits and


Fig. 3. Weight losses recorded as a function of temperature in the (a) non-oxidative and (b) oxidative environments.

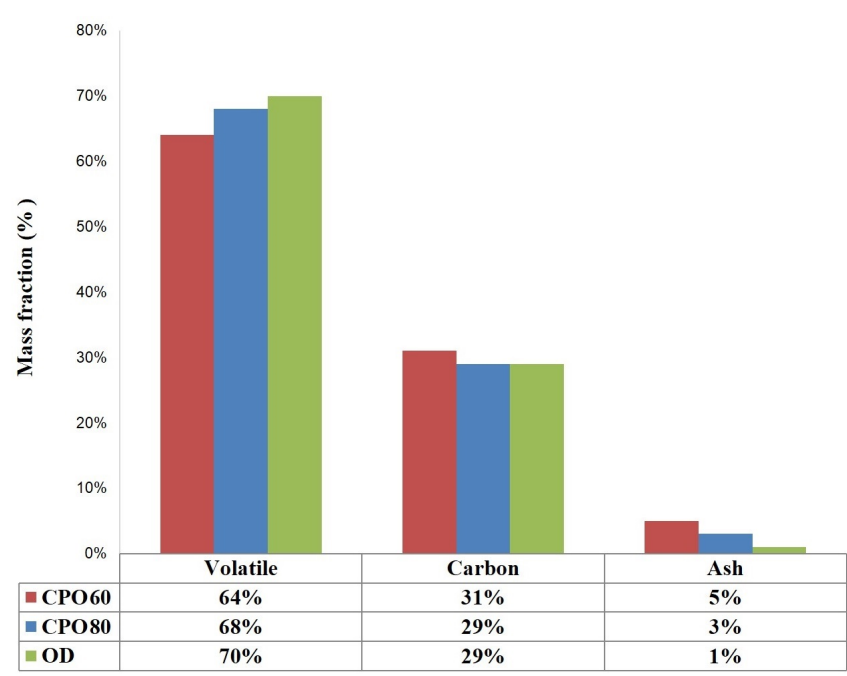

Fig. 4. A summary of the TGA results revealing the mass composition of the deposits formed in response to the different treatments.

contaminants, which could block oil passages and impair the lubricating system. All these actions contribute to the degradation of lubricants (viscosity changes) over time. A too low viscosity would allow metal-tometal contacts and consequently, lead to increased engine wear. While a too high viscosity could increase both the energy required to operate the mechanism and the local heat generation. 




Fig. 5. Deposit reductions obtained by using $\mathrm{CPO}$ at elevated preheating temperature, i.e., $\mathrm{CPO} 80$ vs. CPO60.

In the present study, two main factors could contribute to lubricant viscosity alterations, which could be accompanied with serious engine wears; 1) dilution by fuel and 2) soot contamination. As already pointed out, when straight vegetable oils are used as fuel in CI engines, their high viscosities could lead to poor fuel jet nebulisation, thus causing incomplete combustions and higher in-cylinder carbon deposits (Fig. 2). These deposits could partially be transferred to lubricant as soot. Increasing the soot content of the lubricant not only increments its viscosity, but also owing to the abrasive action of the contaminants, increases the risk of engine wear. On the other hand, a poor fuel jet nebulisation could also result in deeper in-cylinder jet penetration and wall impingement, thus increasing the amount of diluted fuel in the lubricant. The contamination of lubricant by fuel (usually referred to as fuel dilution) is accompanied by marked lubricant viscosity reduction. A dilution of $5 \%$ by volume could reduce lubricant viscosity by approximately $25 \%$, and is usually considered as a clear indication of the need for lubricant change. Fuel dilution is still one of the most important lubricant failure modes in internal combustion engines and usually occurs due to improper air/fuel ratios, excessive piston ring wears, or defective injectors.

The lubricant employed in the present tests was the Total Rubia S40, which is suitable for large diesel engines and complies with the ACEA E2, API $\mathrm{CF} / \mathrm{SF}$, and SAE Grade 40 specifications. With the aim to ascertain the level of engine lubricant contamination caused by the prolonged use of preheated CPO and to understand the effect of preheating temperature, lubricant samples were collected and analysed after the first 100 running hours and then every $50 \mathrm{~h}$ until the end of the $300 \mathrm{~h}$ experiments. Figure 6 a shows the soot content of the lubricant samples as function of engine running time. Accordingly, soot concentration in the lubricant reached $4.8 \mathrm{wt} . \%$ after $300 \mathrm{~h}$ when the engine was operated on OD while considerably higher soot concentrations were recorded in response to $\mathrm{CPO}$ combustion. More specifically, CPO60 and CPO80 led to lubricant soot concentrations of $8.9 \mathrm{wt} . \%$ and $6.7 \mathrm{wt} . \%$ after 300 $\mathrm{h}$ of operation (i.e., $85 \%$ and $40 \%$ increases $v s$. OD).

The same lubricant samples were also examined to determine the level of fuel dilution. As depicted in Figure $6 \mathrm{~b}, \mathrm{a} 3.0 \%(\mathrm{v} / \mathrm{v})$ fuel dilution was measured for OD after $100 \mathrm{~h}$ of operation, reaching $6.1 \%(\mathrm{v} / \mathrm{v})$ by the end of the $300 \mathrm{~h}$ experiment. The data recorded for CPO revealed significantly higher fuel dilution values. CPO60 was associated with a $5.8 \%(\mathrm{v} / \mathrm{v})$ fuel dilution after the first $100 \mathrm{~h}$ of operation (i.e., a $93 \%$ increment in comparison with that of the OD) and $11.8 \%(\mathrm{v} / \mathrm{v})$ upon the completion of the experiment. Similar to the results obtained for soot contamination, increasing the preheating temperature to $80{ }^{\circ} \mathrm{C}$ discounted the fuel dilution phenomenon by over $50 \%$.

Given the higher viscosity of CPO vs. OD (Fig. 1) as well as its stronger soot contamination impact (Fig. 6a), changes in lubricant viscosity were also


Fig. 6. Concentrations of (a) soot and (b) fuel in the lubricant samples as a function of engine operation time.

checked to take into account the combined effect of soot and fuel contaminations. Figure 7a report on the lubricant viscosity measured at 40 ${ }^{\circ} \mathrm{C}$. As can be observed, the use of both OD and CPO caused a progressive deterioration of the lubricant viscosity reduction. However, more pronounced reductions were observed when the engine was operated with $\mathrm{CPO}$ and in particular at the lower preheating temperature. When dealing with internal combustion engine, lubricant viscosity measurements should also be carried out at $100{ }^{\circ} \mathrm{C}$ in order to look into lubricant suitability under the real operating conditions. The results of these measurements as a function of engine running time and for each fuel and preheating temperature are presented in Figure $7 \mathrm{~b}$. Accordingly, the lubricant viscosities measured for OD and CPO80 decreased with almost similar trends up to end of the test period $(300 \mathrm{~h})$, while the use of CPO60 caused a marked decline just after $150 \mathrm{~h}$ of operation.

Based on engine operation manual and lubricant specifications, complete lubricant change should be performed when lubricant viscosity at $100{ }^{\circ} \mathrm{C}$ falls below $10 \mathrm{cSt}$. An alternative indication given in the same manual states that when using OD, complete lubricant change should be carried out every $400 \mathrm{~h}$ even without needing to check lubricant condition 
or viscosity. As can be deduced from the data reported in Figure $7 \mathrm{~b}$, the minimum viscosity limit of $10 \mathrm{cSt}$ was not reached when running the engine with OD for $300 \mathrm{~h}$. By data extrapolation, it could be estimated that the minimum viscosity limit would be reached after $380 \mathrm{~h}$ of continuous operation on $\mathrm{OD}$, quite close to the $400 \mathrm{~h}$ indicated by the engine manufacturer. On the contrary, only $220 \mathrm{~h}$ of operation on CPO60 was enough to reduce the lubricant viscosity below the threshold of $10 \mathrm{cSt}$. This means a $42 \%$ reduction in operating time compared to OD. Preheating at $80{ }^{\circ} \mathrm{C}$ partially extended the operating time to $300 \mathrm{~h}$ (i.e., $20 \%$ less compared with OD) before a complete lubricant change was mandatory (Fig. $7 \mathrm{~b}$ ). In another word, there was a $34 \%$ (76 h) difference between engine operation using CPO60 and CPO80 highlighting the significance of the treatment implemented from the maintenance and consequently economic viewpoints.
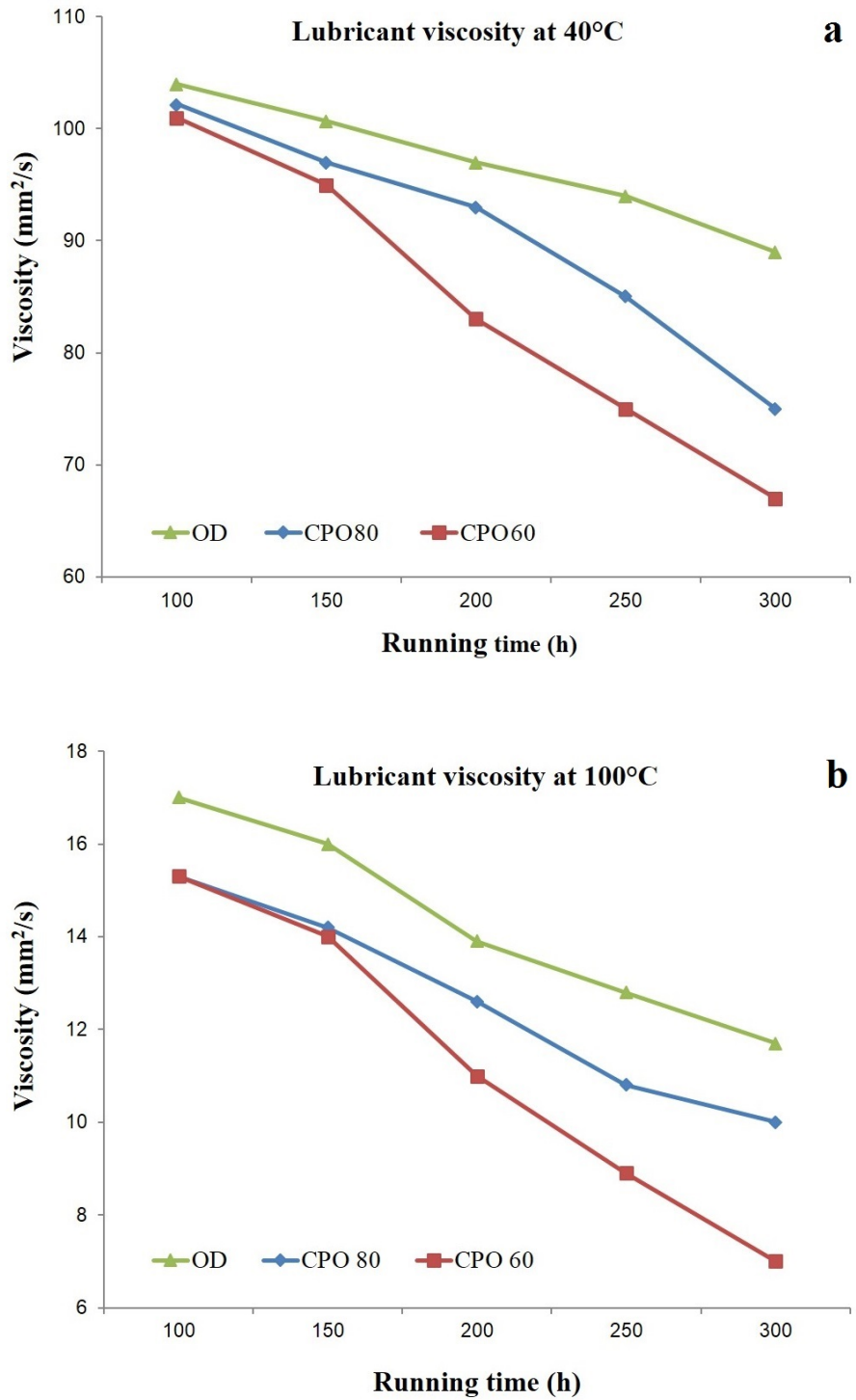

Fig.7. Variations in the viscosity of the lubricant samples at (a) $40{ }^{\circ} \mathrm{C}$ and (b) $100{ }^{\circ} \mathrm{C}$.

Given the high levels of soot and fuel contamination detected in the lubricant as well as the resulting unfavourable impacts on lubricant viscosity vs. operation time, the lubricant samples were also analysed by atomic absorption spectroscopy (AAS) to detect and quantify the presence of metals in the lubricant (in ppm) indicating engine wear (Caine et al., 2004). This in fact indirectly revealed the mechanical state of the engine.

Iron is the most common wear metals and its presence in engine lubricant is associated with the occurrence of wear in piston rings, valve train, rocker arms and cylinder liners. The typical concentration of iron in engine lubricant is in the range $30-70 \mathrm{ppm}$, while $100 \mathrm{ppm}$ is considered as a warning value (Caine et al., 2004; Holloway, 2007). Figure 8a shows the concentration of iron detected in the lubricant samples as a function of engine running time. When using $\mathrm{CPO}$ and up to $250 \mathrm{~h}$ of operation, slightly higher iron concentrations (approx. $20 \mathrm{ppm}$ ) were recorded in the lubricant compared to OD. However, just beyond $250 \mathrm{~h}$ of operation, rapid increases in iron concentrations were observed for both CPO60 and CPO80, crossing the concertation threshold of $100 \mathrm{ppm}$. By the end of the $300 \mathrm{~h}$ experiment, the iron content of the lubricants stood at $168 \mathrm{ppm}$ and $147 \mathrm{ppm}$ for CPO60 and CPO80, respectively. While, the iron content of the lubricant when using OD, stayed just below the 100-ppm threshold throughout the operation. This finding highlights the necessity to carefully consider the extension of the engine continuous operation period when using CPO through accurate lubricant analysis.
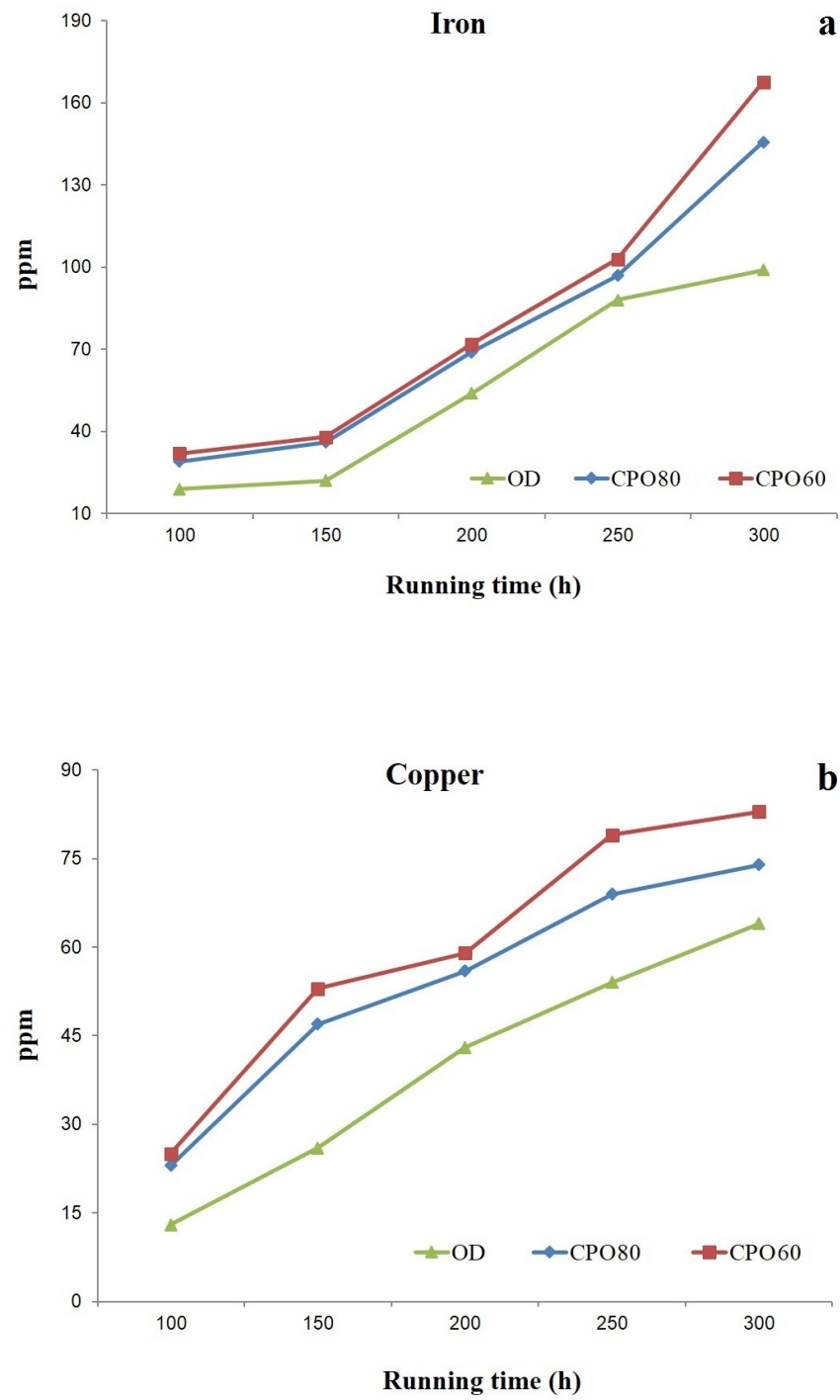

Fig. 8. Concentration of (a) iron and (b) copper detected in the lubricant samples as a function of engine operation time. 
The presence of copper in engine lubricant is usually associated with wear in valve train bushings, wrist pin bushings, cam bushings, and connecting rods bearings. Normal levels of copper in engine lubricant range between 15 and 25 ppm, while $50 \mathrm{ppm}$ is considered as a warning value (Caine et al., 2004; Holloway, 2007). Figure $\mathbf{8 b}$ reports on the copper concentration measured in the lubricant samples. Similar increasing trends were observed all the tested fuels, CPO gave rise to higher cupper concentrations $v s$. OD though. At the end of the $300 \mathrm{~h}$ running period, the use of OD was associated with a $64 \mathrm{ppm}$ copper concentration in the lubricant while $30 \%$ and $16 \%$ higher concentrations were measured for $\mathrm{CPO} 60$ and $\mathrm{CPO} 80$, respectively.


Fig. 9. Concentration of (a) lead and (b) aluminium detected in the lubricant samples as a function of engine operation time.

The presence of lead in engine lubricant is also considered as another indicator of engine wear mostly attributed to bearings (main bearings, connecting rod bearings) or antifriction surfaces. Lead concentration in lubricant should range between 20 and $40 \mathrm{ppm}$, while the warning value is considered to be $50 \mathrm{ppm}$ (Caine et al., 2004; Holloway, 2007). As can be observed in Figure 9a, very low levels of lead were detected in the lubricant samples collected using both $\mathrm{CPO}$ and $\mathrm{OD}$, i.e., safely under the warning value in spite of their increasing trends. Nevertheless, given the recent ban on lead by the European Union End of Life Vehicle (ELV) Directive, even very low concentrations of metals such as lead (in used engine lubricant for instance) could be challenging. As presented, CPO resulted in higher concentrations of lead in engine lubricant and this should be considered when targeting the application of straight vegetable oils such as CPO.

The presence of aluminium in engine lubricant can be traced back to piston scuffing and the levels generally recorded range between 10 and 20 ppm, with 25 ppm regarded as the warning value (Caine et al., 2004; Holloway, 2007). Figure 9b shows the aluminium concentrations measured in the lubricant samples throughout the $300 \mathrm{~h}$ operation period. All the three fuels were characterized by rising trends vs. time, with $\mathrm{CPO} 60$ leading to the highest aluminium concentrations. However, all these values were considerably lower than the values generally reported in the literature. This could be probably ascribed to the particular piston adopted in the engine tested herein, which had an aluminium body and a steel crown.

\section{Conclusions and practical implications}

Extensive series of endurance tests were performed on a large, 8 cylinder, stationary CI engine (operated at $1500 \mathrm{rpm}, 70 \%$ full load for 300 consecutive $\mathrm{h}-14 \mathrm{~h} / \mathrm{d}$ ) with the aim to ascertain the influence of the preheating temperature on both carbon deposits and engine wear caused by the prolonged use of $\mathrm{CPO}$ in comparison with $\mathrm{OD}$. The results obtained were indicative of the favourable impact of preheating of $\mathrm{CPO}$ at higher temperatures (i.e., $80^{\circ} \mathrm{C}$ ) on reducing oil viscosity, which consequently led to more efficient fuel jet nebulization and more complete combustion process. In response to these improved attributes, both deposit formation and engine wear were reduced substantially. More specifically, increasing the preheating temperature from $60{ }^{\circ} \mathrm{C}$ to $80{ }^{\circ} \mathrm{C}$ allowed a carbon deposits reduction of $38 \%$ on cylinder heads, $43 \%$ on engine valves, $30 \%$ on injectors, and $35 \%$ on piston crowns.

The application of CPO was found to result in alterations in the viscosity of engine lubricant. This could be explained by the unfavourable phenomena triggered by using $\mathrm{CPO}$ as fuel, i.e., fuel dilution and soot contamination. $\mathrm{CPO}$ and in particular at lower preheating temperature led to substantially higher soot accumulation in the lubricant throughout the $300 \mathrm{~h}$ of operation $\left(40\right.$ and $85 \%$ increment at $60{ }^{\circ} \mathrm{C}$ and $80{ }^{\circ} \mathrm{C}$ preheating temperatures, respectively, compared with OD). Such high levels of soot contamination could cause sharp increases in lubricant viscosity. Similarly, fuel content in the lubricant was found to experience sharper increases as a function of engine operation time in response to the utilization of $\mathrm{CPO}$ against OD. Overall, for all the tested fuels, the effect of fuel dilution on lubricant properties prevailed that of soot contamination, causing a general viscosity decrease against operation time. The reduction was clearly more pronounced using $\mathrm{CPO}$, above all using the lower preheating temperature. Accordingly, by taking into consideration the minimum lubricant viscosity limit of $10 \mathrm{cSt}$ (at $100{ }^{\circ} \mathrm{C}$ ), it could be concluded that using CPO60 and CPO80, continuous engine operation period (i.e., $400 \mathrm{~h}$ without a complete lubricant change) should be reduced by at $40 \%$ and $20 \%$, respectively. It is suggested to take similar precautions when planning to fuel CI engines with other types of straight vegetable oils.

Finally and as revealed by the AAS analysis, generally higher levels of wear-related metals were measured in the lubricant samples associated with $\mathrm{CPO}$ and in particular at the lower preheating temperature. Among these metals, iron concentration in the engine lubricant well exceeded the warning threshold in response to using $\mathrm{CPO}$, above all with the lower preheating temperature. Accordingly, it could be deduced that when fuelling the engine with $\mathrm{CPO}$, the extension of the continuous engine operation beyond $250 \mathrm{~h}$ should be carefully evaluated.

\section{Acknowledgments}

The authors gratefully acknowledge Moncada Energy Group (www.moncadaenergygroup.com), whose valuable collaboration made this work possible. 


\section{References}

[1] Agarwal, A.K., 2007. Biofuels (alcohols and biodiesel) applications as fuels for internal combustion engines. Prog. Energy Combus. Sci. 33(3), 233-271.

[2] Agarwal, D., Agarwal, A.K., 2007. Performance and emissions characteristics of Jatropha oil (preheated and blends) in a direct injection compression ignition engine. Appl. Therm. Eng. 27(13), 2314-2323

[3] Altin, R., Cetinkaya, S., Yucesu, H.S., 2001. The potential of using vegetable oil fuels as fuel for diesel engines. Energy Convers. Manage. 42(5), 529-538

[4] Aydin, H., Bayindir, H., 2010. Performance and emission analysis of cottonseed oil methyl ester in a diesel engine. Renewable Energy. 35(3), 588-592.

[5] Basinger, M., Reding, T., Rodriguez-Sanchez, F.S., Lackner, K.S., Modi, V., 2010. Durability testing modified compression ignition engines fueled with straight plant oil. Energy. 35(8), 3204-3220.

[6] Caine, A., Haycock, R., Hillier, J., 2004. Automotive lubricants reference book, Second Edition. SAE Int. Prof. Eng. Publishing.

[7] Canakci, M., Ozsezen, A.N., Turkcan, A., 2009. Combustion analysis of preheated crude sunflower oil in an IDI diesel engine. Biomass Bioenergy. 33(5), 760-767

[8] Çelikten, I., Koca, A., Arslan, M.A., 2010. Comparison of performance and emissions of diesel fuel, rapeseed and soybean oil methyl esters injected at different pressures. Renewable Energy. 35(4), 814-820.

[9] Çelikten, I., Mutlu, E., Solmaz, H., 2012. Variation of performance and emission characteristics of a diesel engine fueled with diesel, rapeseed oil and hazelnut oil methyl ester blends. Renewable Energy. 48, 122 126.

[10] De Almeida, S.C., Belchior, C.R., Nascimento, M.V., Vieira, L., Fleury, G., 2002. Performance of a diesel generator fuelled with palm oil. Fuel. 81(16), 2097-2102.

[11] Earth's $\mathrm{CO}_{2}$ Home Page, 2018.

[12] Erickson, D.R., 1990. Edible Fats and Oils Processing: Basic Principles and Modern Practices: World Conference Proceedings. The Am. Oil Chem. Soc

[13] Esteban, B., Riba, J.R., Baquero, G., Rius, A., Puig, R., 2012. Temperature dependence of density and viscosity of vegetable oils. Biomass Bioenergy. 42, 164-171.

[14] Fazal, M.A., Haseeb, A.S.M.A., Masjuki, H.H., 2011. Biodiesel feasibility study: an evaluation of material compatibility; performance; emission and engine durability. Renew. Sust. Energy Rev. 15(2), 13141324

[15] Franco, Z., Nguyen, Q.D., 2011. Flow properties of vegetable oildiesel fuel blends. Fuel. 90(2), 838-843.

[16] Gokalp, B., Buyukkaya, E., Soyhan, H.S., 2011. Performance and emissions of a diesel tractor engine fueled with marine diesel and soybean methyl ester. Biomass Bioenergy. 35(8), 3575-3583.

[17] Graboski, M.S., McCormick, R.L., 1998. Combustion of fat and vegetable oil derived fuels in diesel engines. Prog. Energy Combust. Sci. 24(2), 125-164.

[18] Heywood, B.J., 1988. Internal combustion engine fundamentals. New York, McGraw-Hill International Editions.

[19] Holloway, M., 2007. The Oil Analysis Handbook: A Comprehensive Guide to Using and Understanding Oil Analysis. Certified Labs, NCH Corporation.

[20] Husnawan, M., Masjuki, H.H., Mahlia, T.M.I., Saifullah, M.G., 2009. Thermal analysis of cylinder head carbon deposits from single cylinder diesel engine fueled by palm oil-diesel fuel emulsions. Appl. Energy. 86(10), 2107-2113

[21] Kalam, M.A., Masjuki, H.H., 2004. Emissions and deposit characteristics of a small diesel engine when operated on preheated crude palm oil. Biomass Bioenergy. 27(3), 289-297.

[22] Kibbey, T.C.G., Chen, L., Do, L.D., Sabatini, D.A., 2014. Predicting the temperature-dependent viscosity of vegetable oil/diesel reverse microemulsion fuels. Fuel. 116, 432-437.

[23] Kubátová, A., Luo, Y., Štávová, J., Sadrameli, S.M., Aulich, T., Kozliak, E., Seames, W., 2011. New path in the thermal cracking of triacylglycerols (canola and soybean oil). Fuel. 90(8), 2598-2608.
[24] Kumar, M.S., Bellettre, J., Tazerout, M., 2009. The use of biofue emulsions as fuel for diesel engines: a review. Proc. Inst. Mech. Eng., Part A: J. Power Energy. 223(7), 729-742.

[25] Iodice, P., Senatore, A., 2016. Atmospheric pollution from point and diffuse sources in a National Interest Priority Site located in Italy. Energy Environ. 27(5), 586-596.

[26] Iodice, P., Langella, G., Amoresano, A., 2018. Ethanol in gasoline fuel blends: effect on fuel consumption and engine out emissions of SI engines in cold operating conditions. Appl. Therm. Eng. 130, 1081-1089.

[27] Liaquat, A.M., Masjuki, H.H., Kalam, M.A., Fazal, M.A., Khan, A.F., Fayaz, H., Varman, M., 2013. Impact of palm biodiesel blend on injector deposit formation. Appl. Energy. 111, 882-893.

[28] Lim, T.H., Bari, S., Yu, C.W., 2002. Using crude palm oil (CPO) as diesel engine fuel. ASEAN J. Sci. Technol. Dev. 19(2), 1-14.

[29] Maher, K.D., Bressler, D.C., 2007. Pyrolysis of triglyceride materials for the production of renewable fuels and chemicals. Bioresour. Technol. 98(12), 2351-2368

[30] Masjuki, H., Abdulmuin, M.Z., Sii, H.S., 1996. Investigations on preheated palm oil methyl esters in the diesel engine. Proc. Inst. Mech. Eng., Part A: J. Power Energy. 210(2), 131-138.

[31] Mofijur, M., Masjuki, H.H., Kalam, M.A., Atabani, A.E. Shahabuddin, M., Palash, S.M., Hazrat, M.A., 2013. Effect of biodiesel from various feedstocks on combustion characteristics, engine durability and materials compatibility: a review. Renew. Sust. Energy Rev. 28, 441-455.

[32] Ndayishimiye, P., Tazerout, M., 2011. Use of palm oil-based biofuel in the internal combustion engines: performance and emissions characteristics. Energy. 36(3), 1790-1796.

[33] Nwafor, O.M.I., 2003. The effect of elevated fuel inlet temperature on performance of diesel engine running on neat vegetable oil at constant speed conditions. Renewable Energy. 28(2), 171-181.

[34] Ong, H.C., Mahlia, T.M.I., Masjuki, H.H., Norhasyima, R.S., 2011 Comparison of Palm oil, Jatropha curcas and Calophyllum inophyllum for biodiesel: a review. Renew. Sust. Energy Rev. 15(8), 3501-3515.

[35] Saravanan, S., Nagarajan, G., Rao, G.L.N., Sampath, S., 2007. Feasibility study of crude rice bran oil as a diesel substitute in a DICI engine without modifications. Energy Sust. Dev. 11(3), 83-92.

[36] Shaheed, A., Swain, E., 1999. Combustion analysis of coconut oil and its methyl esters in a diesel engine. Proc. Inst. Mech. Eng., Part A: J. Power Energy. 213(5), 417-425.

[37] Sharon, H., Jayaprakash, R., Karthigai Selvan, M., Soban Kumar, D.R., Sundaresan, A., Karuppasamy, K., 2012a. Biodiesel production and prediction of engine performance using SIMULINK model of trained neural network. Fuel. 99, 197-203.

[38] Sharon, H., Karuppasamy, K., Soban Kumar, D.R., Sundaresan, A., 2012b. A test on DI diesel engine fueled with methyl esters of used palm oil. Renewable Energy. 47, 160-166.

[39] Shu, G., Dong, L., Liang, X., 2012. A review of experimenta studies on deposits in the combustion chambers of interna combustion engines. Int. J. Engine Res. 13(4), 357-369.

[40] Sidibé, S.S., Blin, J., Vaitilingom, G., Azoumah, Y., 2010. Use of crude filtered vegetable oil as a fuel in diesel engines state of the art: literature review. Renew. Sust. Energy Rev. 14(9), 2748-2759.

[41] Srivastava, A., Prasad, R., 2000. Triglycerides-based diesel fuels. Renew. Sust. Energy Rev. 4(2), 111-133.

[42] Wander, P.R., Altafini, C.R., Colombo, A.L., Perera, S.C., 2011 Durability studies of mono-cylinder compression ignition engines operating with diesel, soy and castor oil methyl esters. Energy. 36(6), 3917-3923

[43] Ye, Z., Meng, Q., Mohamadian, H.P., Wang, J.T., Chen, L., Zhu, L., 2007. Investigation of deposit formation mechanisms for engine in-cylinder combustion and exhaust systems using quantitative analysis and sustainability study. Int. J. Thermophys. 28(3), 10561066.

[44] Yilmaz, N., 2011. Temperature-dependent viscosity correlations of vegetable oils and biofuel-diesel mixtures. Biomass Bioenergy. 35(7), 2936-2938 
[46] Yusaf, T.F., Yousif, B.F., Elawad, M.M., 2011. Crude palm oil fuel for diesel-engines: experimental and ANN simulation approaches. Energy. 36(8), 4871-4878. 